UDK: 168.2::574-053.1:28

Stručni rad

Primljeno: 2. 10. 2020.

Prihvaćeno za štampu: 23. 11. 2020.

\author{
Dr. sc. Fatima Muhamedagić, docent \\ Univerzitet u Bihaću \\ Biotehnički fakultet \\ E-mail:fatima.mubamedagi@@gmail.com
}

\author{
Dr. sc. Mirsad Veladžić, redovni professor \\ Univerzitet u Bihaću \\ Biotehnički fakultet \\ E-mail:mveladzi@@yahoo.com
}

\title{
ANALIZA ULOGE ČOVJEKA U OKOLIŠU I GLOBALNIH EKOLOŠKIH PROBLEMA DANAŠNJICE S KRATKIM OSVRTOM NA ISLAM
}

\section{Sažetak}

Covjek u ekologiji kao multidisciplinarnoj naučnoj oblasti, jedan je od ključnih ekoloških faktora okolisa. Gledano historijski on u svojoj egzistenciji neprestano mjenja $i$ utice na prirodni okolis $i$ prilagođava ga svojim potrebama. Naime, sagledavajući opíenito, svjedoci smo da je današnje stanje na Zemlji sa stanovista uticaja covjeka i ekologije uveliko narušeno. Takoder, svjedoci smo mnogostrukih irmjena i posljedica narušavanja prirodnog okoliša koje se pojavljuju u kontekstu globalnih ekoloških problema ili cak i ekoloških kriza

Neki od vecih ekoloških problema s kojima se susreće današnji čovjek su: klimatske promjene, pojava „efekat staklenika“", ośtećenje ozonovog omotača i pojava tzv. ozonskih "rupa", onečišćenje medija okoliša kao što su tlo voda i zrak, smanjivanje biodiverziteta, otpad, nekontrolisana eksploatacija prirodnih resursa, radioaktivnost, sirenje pustinja i drugo.

Globalni ekološki problemi, odnosno njihov nastanak poveauje se s nastankom neracionalnog odnosa $i$ stvaranja rascjepa izmedu samog covjeka $i$ prirode. Pored pomenutog njïhov nastanak se takoder povezuje is posljedicom djelovanja raqlicitih izvora zagadenja u okolišs. 
Upravo zbog svega pomenutog u radu se analizira $i$ obraduju uloga corjeka kao ekološkog faktora $i$ neki od navedenih globalnih ekoloških problema današnjice uzimajuci u obzir kratki islamski aspek.t.

Ključne riječi: ekologija, ekološki faktori, covjek, globalni ekološki problemi

\section{UVODNI DIO}

Ekologija je nastala relativno kasno, u drugoj polovini 19. vijeka kada je prvi put spomenuta u knjizi Opća morfologija životinja (Generale morholologie der organizmen) Ernsta Haeckela (1866). Neki do vodećih ekologa 20. vijeka su Rachel Carston, autorica poznate knjige Tiho proljeće (The Silent Spring) i Eugenije Pleasants Odum autora više izdanja knjiga Osnove ekologije (Fundamentals of Ecology).

Sam naziv ekologija počinje od grčkih riječi koje se sastoje iz dva dijela:

- oĩkos-oikos = dom, prebivalište, kuća, stanište, okućnica

- $\quad \lambda o \gamma i ́ \alpha-\operatorname{logos}=$ nauka, znanje, izučavanje, rasprava

Iako danas postoji više definicija ekologije, većina današnjih stavova je usaglašena oko toga da ekologija predstavlja multidisciplinarnu nauku koja se bavi izučavanjem kompleksa međusobno zavisnih odnosa i interakcija između organizama i okoliša (prirodnog i vještačkog) ili općenito biosfere (prirodne ili izmijenjene) (Muhamedagić i sar. 2020).

Upravo zbog činjenice da je čovjek jedan od organizama u okolišu, njegov život, odnosno, njegova egzistencija kroz vrijeme se može sagledati kroz njegovo djelovanje i mijenjanje okoliša u cilju zadovoljavanja svojih životnih potreba.

Okoliš (eng. Environment) predstavlja komponente okoline (tlo, zrak, voda, biosfera, i izgrađeni tj. vještački okoliš koji je nastao kao rezultat ljudske aktivnosti i koji je kao takav sastavni dio okoliša), određene sisteme (ekosisteme), procese i strukturu okoliša ${ }^{1}$. Jednostavno rečeno, za okoliš se može reći da predstavlja sve ono (tlo, voda, zrak, biodiverzitet) što okružuje čovjeka.

${ }^{1}$ Zakon o zaštiti okoliša (Službene novine Federacije Bosne i Hercegovine br. 33/03 i 38/09) 
Međutim, u današnjem vremenu pored ostalog, sve više se ističu i uticaji na okoliš raznih ekoloških faktora kao i promjene u okolišu koje su nastale kao posljedice tih uticaja.

\section{EKOLOŠKI FAKTORI}

Općenito u okolišu djeluju ekološki faktori od kojih zavisi život organizama koji žive na tom području. Sve komponente okoliša različite prirode, fizičke, hemijske ili biološke kojima su izloženi organizmi, nazivaju se ekološkim faktorima. Oni se dijele na dvije osnovne grupe:

- Abiotički (neživi faktori ili faktori anorganskog porijekla) koji se opet razvrstavaju na:

- Klimatske - odnose se na klimatske parametre kao što su: svjetlost, temperatura, oborine (kiša, led, slana, inje, rosa, snijeg), vjetar, vlažnost, pritisak i drugo.

○ Edafske - obuhvataju fizičke, hemijske i biološke osobine tla te stijena na kojima se razvija tlo (kiselost tla, mehanički humus, poroznost i slično).

- Orografske - obuhvataju osobine reljefa (nadmorska visina, nagib terena, ekspozicija, stepen razuđenosti reljefa i tako dalje).

- Biotički (živi faktori ili faktori organskog porijekla) koji se odnose na različite organizme i njihove međusobne odnose koji mogu biti u simbiozi ili ne (antagonizam) U grupi biotičkih ekoloških faktora nalazi se i čovjek.

Pored pomenute podjele često se, prema porijeklu, navodi i podjela na prirodne ekološke faktore i vještačke ekološke faktore. U ovoj podjeli pod prirodnim ekološkim faktorima se podrazumijevaju svi oni faktori koji postoje sami po sebi u prirodnoj biosferi tj. koji nisu „nastali” od strane čovjeka. Ova grupa faktora se uklapa u ciklične procese i ne remeti ekološku ravnotežu. Druga grupa, takozvani vještački ekološki faktori se odnosi na one faktore koje je ,proizveo čovjek” u okvirima izmijenjene biosfere (tehnosfere). Često se posljedice ovih faktora naglašavaju i u okvirima globalnih ekoloških problema (Muhamedagić i sar. 2020). 


\section{1. Čovjek kao ekološki faktor, njegova uloga i uticaj}

Gledano s aspekta ekologije, čovjek kao dio biotičkih ekoloških faktora u okolišu, kroz svoje egzistiranje i djelovanje, kao dominantan i značajan ekološki faktor, nastupa u opće poznatoj ulozi takozvanog „kreatora okoliša”. Njegova uloga kreatora se najčešće pojavljuje kroz:

- Pozitivno djelovanje u cilju održivosti i održivog upravljanja: pošumljavanje, očuvanja biodiverziteta, razne sanacije, integralno upravljanje u okolišu (tlo, zrak, voda, otpad i drugo), ekološki monitoring, kontrola i upavljanje ekološkim rizicima, zakonodavstvo u oblasti ekologije i održivog upravljanja okolišem i slično;

- Negativno djelovanje u cilju narušavanja ekološke ravnoteže u ekosistemima: nekontrolisana sječa šuma i eksploatacija resursa, selektiranje i/ili uništavanje biodiverziteta, uticaj saobraćaja na okoliš, „proizvođač“ kiselih kiša, širenje industrijalizacije i urbanizacije (gradovi, beton), nekontrolisane migracije, zagađivač i degradator medija okoliša (voda, tlo, zrak) i dr. Naprimjer, Krznar (2007) o čovjeku govori kao o uništavatelju prirode (homo destructor) koji je, gledano biološki, jedino biće koje mjenja okoliš u skladu sa svojim potrebama i koji se dobro prilagođava.

Dvostruko istupanje i djelovanje čovjeka u okolišu može se sagledati s dva aspekta kao:

Ljubitelj prirode i okoliša - može biti svaki čovjek koji voli prirodu, okoliš, šetnje, planinarenje, rekreacije i slično. Međutim, ljubitelji okoliša i prirode često iz neznanja ili nemara mogu uzrokovati štetne posljedice poslije svojih „posjeta“ (požari, otpad, berba rijetkih biljnih vrsta i slično). Ovi negativni uticaji mogu imati ekološke posljedice po okoliš.

Ekolog - ne može biti svako, jer je ekolog naučnik koji poznaje i bavi se izučavanjem ekologije kao mulitidisciplinarne naučne oblasti. On izučava uloge i vrijednosti bivstvovanja svake jedinke unutar biocenoza i poštuje ciklične zakonitosti u prirodi. U svom istraživanju ekolog prilazi sistematski i studiozno poznavajući međusobne sinteze između biocenoza, biogeohemijskih ciklusa, reverzibilnih i nereverzibilnih postupaka kao i posljedica od strane čovjeka. Ekolog svojim „posjetama“ u okolišu ne izaziva negativne uticaje i ne uzrokuje štetne 
posljedice. On stremi održavanju ekološke ravnoteže i postizanju održivog razvoja.

Svi uticaji koji su povezani s čovjekovim djelovanjem na okoliš svrstavaju se u antropogene. Suprotno njima uticaji koji su nevezani za njegovo djelovanje, a javaljaju se kroz vulkanske erupcije, zemljotrese ili druge nepogode nazivaju se prirodnim.

Globalni okoliš je općenito izložen različitim izvorima zagađenja, uticajima ili pojavama koje ugrožavaju njegovo funkcionisanje. Prirodni uticaj na ekosisteme oduvijek je bio i postojao, postoji i danas. Njegov uticaj ne narušava ekološku ravnotežu, cikličnost, te je reverzibilnog (povratnog) i samoobnovljivog karaktera. Antropogeni uticaji (uticaj od strane čovjeka) pojavili su se nastankom čovjeka. Ovi uticaji su opasniji, ozbiljniji, kompleksniji i često su ireverzibilnog (nepovratnog) karaktera $\mathrm{s}$ višestrukim posljedicama. Najčešći antropogeni izvori su: industrijalizacija, urbanizacija, korištenje nuklearne energije, sječa šuma, otpad, eksploatacija mineralnih sirovina, emisije, imisije i drugo.

\section{GLOBALNI EKOLOŠKI PROBLEMI}

Veliki broj globalnih ekoloških problema je nastao kao posljedica neracionalnog odnosa i stvaranja rascjepa između samog čovjeka i prirode. Globalni ekološki problemi nastali su i kao posljedica djelovanja različitih izvora zagađenja.

\subsection{Efekat staklenika}

Efakat staklenika (eng. Greenhouse efect) definiše se kao pojava gdje dolazi do porasta vrijednosti temperature zraka u atmosferi, a koja je izazvana stakleničkim plinovima kao što su: ugljendioksid $\left(\mathrm{CO}_{2}\right)$, metan $\left(\mathrm{CH}_{4}\right)$, azotnidioksid $\left(\mathrm{NO}_{2}\right)$, vodena para $\left(\mathrm{H}_{2} \mathrm{O}\right)$, ozon $\left(\mathrm{O}_{3}\right)$ i hlorofluorougljici (CFC jedinjenja). Životni vijek stakleničkih plinova kao i njihov potencijal je različit. Staklenički plinovi u atmosferi zrače energijom u svim smjerovima. Dio ovog zračenja usmjeren je prema površini Zemlje pri čemu dolazi do njenog zagrijavanja (Smil, 2003).

Efekat staklenika je proces zagrijavanja Zemljine površine i donjih slojeva Zemljine atmosfere selektivnim propuštanjem toplotnog 
zračenja. Kod ovog procesa, zračenje koje dolazi iz atmosfere zagrijava površinu planete na temperaturu veću od one koja bi bila bez tog zračenja iz atmosfere (IPPC, 2013).

Obično su poznata dva efekta: prirodni efekat i antropogeni efekat staklenika. Prirodnom efektu najviše doprinosi vodena para i drugi staklenički plinovi. Antorpogeni efekat je vezan za čovjeka koji ima za posljedicu proizvodnju i nastanak stakleničkih plinova.

\subsection{Oštećenje ozonskog omotača i nastanak ozonskih "rupa"}

Oštećenje ozonskog omotača poznato je kao pojava ozonske rupe. Ozonska rupa (eng. ozone hole) kao okolišni problem datira još iz 70tih godina 20. vijeka, kada je ustanovljeno da neki hemijski proizvodi koje je proizveo čovjek razgrađuju ozon $\left(\mathrm{O}_{3}\right)$ i slabe ozonski omotač. Ozon je inače plin i predstavlja alotropsku modifikaciju kiseonika.

Pojava „Ozonska rupa“ se, ustvari, pogrešno shvata jer kada bi uistinu postojale ,rupe“ u stratosferi (sloj atmosfere), živi svijet na Zemlji bio bi uništen. One predstavljaju određena područja u stratosferi gdje je koncentracija ozona smanjena, odnosno sadržaj ozona dosta je rjeđi od uobičajenog. Zbog ove pojave ozon ne može u potpunosti opravdati svoju ključnu ulogu u regulaciji klime i očuvanja biosfere, odnosno Zemlje.

Opće je poznato da postoje dvije vrste ozona i to „dobri“ i „loši“ ozon.

Dobri ozon predstavlja prirodni ozon koji pozitivno utiče na život na Zemlji. On pokreće hemijske procese i vrši eliminaciju mnogih zagađujućih materija kao što su: $\mathrm{CO}, \mathrm{CO}_{2}, \mathrm{CH}_{4}$ i drugih stakleničkih plinova. Smatra se korisnim za zdravlje ljudi i ostalih formi života zato što upija ultraljubičaste UV-B zrake ${ }^{2}$. Za razliku od njega loši ozon predstavlja onu vrstu ozona koji je nastao djelatnošću čovjeka (troposferski ozon, tehnogeni ozon). Ova vrsta ozona nastaje u blizni površine Zemlje iz hemijskih procesa i učešća zagađujućih plinova koje je proizveo čovjek. Loše utiče na zdravlje ljudi i na život općenito.

\footnotetext{
${ }^{2}$ UV-B zrake su ultraljubičase zrake srednjevalnog područja između $315 \mathrm{~nm}$ i 280 nm, a uzrokuje rak kože, slabljene imuniteta, oštećenje biljnog svijeta, oštećenje podvodnih ekosistema i drugo.
} 
Povećevanje sadržaja ovog ozona dovodi do zagrijavanja površine Zemlje kao i slabljenja upijanja UV-B zraka.

\subsection{Klimatske promjene}

Globalne klimatske promjene (eng. Global klimate change) predstavljaju promjenu klime planetarnog razmjera koja se direktno ili indirektno uglavnom pripisuje antropogenim posljedicama, odnosno, čovjekovim djelatnostima.

Uglavnom do promjena dolazi zbog sve većeg nagomilavanja proizvedenih stakleničkih plinova, prije svega, ugljen dioksida $\left(\mathrm{CO}_{2}\right)$ kao i drugih stakleničkih plinova poput: metana $\left(\mathrm{CH}_{4}\right)$, oksidi azota $\left(\mathrm{NO}_{\mathrm{x}}\right)$ i CFC jedinjenja - freoni tj. jedinjenja hlorofluorugljika (WMO, 2018). Poznato je da klimatske promjene imaju različite posljedice na: promjene nivoa mora, biljni i životinjski svijet i masovno izumiranje mnogih vrsta (biljnih i životinjskih). One, također, utiču na ljudska bića i njihovo zdravlje.

\subsection{Onečišćenje i/ili zagađenje medija okoliša}

Često se koriste termini onečišćenje i/ili zagađenje koje uzrokuje značajne probleme u okolišu, no između njih postoji razlika. Kod onečišćenja svaki nastali poremećaj ili promjena kod određenih karakteristika (fizičkih, bioloških ili hemijskih) u koncentraciji ili količini može se vratiti u prvobitno stanje. Onečišćenje ima reverzibilan karakter. Kod zagađenja svaki nastali poremećaj ili promjena ne može se vratiti u prvobitno stanje i dolazi do trajnog oblika promjene kod sastava i karakteristika okoliša. Zagađenje je, ustvari, onečišćenje većeg intenziteta i ono ima ireverzibilan karakter. Bilo koja vrsta onečišćenja i/ili zagađenja može biti uzrokovana prirodnim putem (samo od sebe) i vještačkim putem (posredstvom čovjeka).

Govoreći o onečišćenju i/ili zagađenju medija okoliša tj. tla, zraka i vode koriste se termini: za tlo - pedozagađenje (kontaminacija); za zrak - aerozagađenje i za vode - hidrozagađenje. 


\subsection{Smanjenje biodiverziteta}

Biodiverzitet (eng. Biodiversity) ili biološka raznolikost (grč. ßios „bios“, lat. diverssus, particip prošli od dīvertere - „da se skrene“) označava termin koji opisuje činjenicu da na Zemlji nikad nisu postojala, ne postoje, niti (teorijski) mogu postojati dva biološki istovjetna živa sistema. Općenito biodiverzitet predstavlja ukupnu raznolikost živog svijeta na planeti Zemlji (biosferi). On je jedan od najpouzdanijih pokazatelja globalnih promjena. Savremena nauka u biodiverzitetu razlikuje sljedeće nivoe biološke raznolikosti: genetička raznolikost (eng. Genetic diverisity); specijska raznolikost (eng. Species diversity); ekosistemska raznolikost (eng. Diversity of ecosystems); geološka raznolikost (eng. Geological divesity) i pejzažna raznolikost (eng. Landscape diversity).

U studiju Global Biodiversity Strategy - GBS (WRI, IUCN i UNEP, 1992) i u prikazu Global Biodiversity Assessment - GBA (UNEP, 1995) navode se uzroci smanjenja svjetskog biodiverziteta kao naprimjer: krčenje i devastacija šuma; širenje poljoprivrednih površina, ljudskih naselja; narušavanje ili uništavanje staništa; globalna promjena klime i dr. Withgott i Brennan (2005), također, navode pet osnovnih faktora koji dovode do gubitka biodiverziteta - H.I.P.P.O.: Habitat Loss (Gubitak staništa), Invasive Species (Invazivne vrste), Pollution (Zagađenje), Population Growth (Brzi rast ljudske populacije) i Overconsumption (Prekomjerna eksploatacija).

\subsection{Otpad}

Otpad (eng. Waste) je pojam koji označava nešto odbačeno, što trenutnom vlasniku nije potrebno i odlaže se na okolišno prihvatljiv način ${ }^{3}$. Danas u segmentu problematike oko otpada se uveliko rješava i u sistemu je integralnog načina upravljanja otpadom. Postoji pozitivan opći koncept 4R (Reduce, Reuse, Recycle i Recover) + 3E (Educate, Economise i Enforce). Tjell (2005) navodi da je u EU razrađen pristup, poznat kao princip hijerarhije otpada (eng. waste hierarchy princip), koji uključuje izbjegavanje stvaranja otpada i reklamiranje njegove prerade, reciklaže i kompostiranja, ponovne upotrebe i spaljivanja.

\footnotetext{
${ }^{3}$ Izvor: Direktiva EU 2008/98/EZ
} 


\subsection{Resursi}

Resurs (franc. la ressource $=$ sredstvo, izvor i lat. Resurgere - izvirati) označava sredstvo koje je potrebno za provođenje ili dovršavanje neke radnje. U ekologiji pri korištenju riječi resursi vrlo često se koristi naziv prirodni resursi. Prirodni resursi se nalaze svugdje oko nas i oni mogu biti sunčeva svjetlost, atmosfera (jačina vjetra i sl.) voda (plima i oseka, brzoprotočne vode i sl.), tlo, razna mineralna dobra, biljke, životinje, pa čak i čovjek. Čovjek je također resurs.

Oduvjek je, gledano kroz historiju, u svijetu trajala „borba“ za raznim prirodnim resursima i činjenica je da su se uglavnom i svi ratovi upravo vodili zbog njih. U dugoj historiji čovječanstva mnoge stijene, metali, ugalj, a kasnije nafta, plin, uran i druge vrste prirodnih mineralnih bogatstava imale su veliku važnost u samom opstanku ljudskog društva. Među prvim rudama od velikog značaja za čovjeka bila je kamena so, a među prvim poznatim metalima bili su zlato i bakar. Općenito se može zaključiti da je postojala i još uvijek postoji velika potreba za raznim prirodnim resursima.

\section{ASPEKT ISLAMA}

Ekologija nije nešto strano islamu. Nju je njegovao vjerozakon svakog od ranijih poslanika, a posebno je to naglasio posljednji poslanik Muhammed, a.s., koji je podsticao na čišćenje dvorišta i održavanja čistoće u okolišu. Sama njegova izreka: „Čistoća je pola vjere“ dovoljno ukazuje na to koliku je važnost pridavao čišćenju. Od njega je preneseno da je zabranjeno zagađivanje okoliša i uznemiravanje ljudi, kao i ostalih živih bića.

Također, poslanik Muhammed, a.s., nije dozvoljavao da se čini nužda u vodu, pogotovu stajaću, niti da se nužda obavlja na putu kuda prolaze ljudi. Posebno je pohvalio uklanjanje s puta svega onoga (grane, staklo i tome slično - općenito otpad) što smeta prolaznicima i to je ubrojao u sastavne dijelove vjerovanja: „Islam se sastoji od sedamdeset i nekoliko dijelova, najvažnije od toga je reći La ilahe illellah / Nema drugog boga osim Allaha, a posljednji ukloniti s puta ono što smeta prolaznicima." Koliko je Muhammed, a.s., podržavao brigu za čist, zdrav i lijep okoliš govori ova njegova izreka: „Kada bi nastupio Kijametski dan, a u ruci jednog od vas bila sadnica, neka je posadi.“ 
Naprimjer, kada se govori ili piše o ekologiji pridaje se značaj uređenju okoliša. Poslanik, a.s., je rekao: „Allah je lijep $i$ voli ljepotu.“, a činjenica jeste da je neuređen okoliš ružan, no pored toga može biti i opasan ukoliko je još zagađen.

Ekologija pokušava da nađe odgovore i rješenja brojnim problemima okoliša koji nas sve više zatrpavaju. Svi ti problemi su uglavnom ljudskog porijekla i upravo im je čovjek osnovni uzrok (antropogeni uticaj) jer je, nažalost, po prirodi „zaboravno“ biće na povjereni mu emanet.

Svaki je čovjek, musliman, s aspekta islamskih načela, kao razumno biće kojim ga je obdario Stvoritelj dužan svojom umjerenošću, čestitošću i odgovornošću živjeti skladno Božijoj volji, odnosno, težiti očuvanju okoliša koji nam je jedini na raspolaganju u ovom ovozemaljskom životu. Očuvanjem okoliša odaje se priznanje Stvoritelju, ne remeti se Njegov sklad i postiže se održivi razvoj.

U Kur'anu se koristi naziv ajet - znak kao što se koristi i za pojmove i pojave kosmičkih prostranstava. Tako su nebesa i Zemlja, smjena dana i noći te kiša koju Allah spušta (cikličnost), raznovrsnost životinja na Zemlji (biodiverzitet), kretanje vjetrova, oblaci koji predano jezde (atmosferske ciklone) označeni kao ajeti - znakovi ${ }^{4}$. „, A koliko samo ima znakova na nebesima i Zemlji, pokraj kojih prolaze, okrećući glave od njih. "5 Da bi ukazao na značaj svakog obzira stvorenog Allah, dž.š., često koristi zakletve: „,Tako Mi neba i Danice. "6, , Tako Mi zore. "7; „, Tako Mi Sunca i svjetlosti njegove, i Mjeseca kada ga prati ustopice. "8 i daje dodatan razlog odnosa punog poštovanja.

Svjedoci smo globalnih ekoloških problema koji su u velikoj mjeri uzrokovani od strane čovjeka (antropogeni uticaj) što vuče ka ekološkoj opasnosti jer se remeti red, Božiji red (sunnetullah), zakonitosti po kojima opstoje i traju svi obziri stvorenih svjetova. „A kada im se kaže:

\footnotetext{
${ }^{4}$ Izvor: Kur'an. 2: 164; 12: 105, 17: 12; 36: 33 i 36: 37.

${ }^{5}$ Izvor: Sura Jusuf, 105.

${ }^{6}$ Izvor: Sura Et-Tarik, 1.

${ }^{7}$ Izvor: Sura El-Fedžr, 1.

${ }^{8}$ Izvor: Sura Eš-Šems, 1 i 2.
} 
„Ne činite nered na Zemlji“, oni vele, „Mi red pravimo.“ A nije tako. Oni stvarno, bezosjećajno, nered čine ${ }^{\text {" } 9}$.

\section{ZAKLJUČAK}

Većina reverzibilnih $\mathrm{i} / \mathrm{ili}$ ireverzibilnih negativnih posljedica nastalo je zbog (ne)savjesnog ponašanja čovjeka kao jedinke i kao ključnog ekološkog faktora na Zemlji (biosferi). Općenito, problemi su obično simptomi nekog poremećaja koji se prepoznaju kod nedostatka vjere, morala, duhovnih vrijednosti, u pohlepi ili pretjeranoj potrebi zadovoljavanja čovjekovih vlastitih želja. Cijela planeta Zemlja (biosfera) je skup raznovrsnih ekosistema koji su, ustvari, jedinstveno funkcioniranje prirodnog, odnosno božanskog reda i poretka u našem užem i širem prirodnom okruženju. Čovjek, djelujući lokalno, može dati svoj doprinos u očuvanju ovog reda i poretka, prije svega svojim zdravim razumom, svojom umjerenošću, čestitošću, urednošću, odgovornošću i slično. O svim ovim vrlinama čovjeka, islam vodi računa te su zbog toga islamska načela življenja garancija sigurne budućnosti na Zemlji.

Krajnje je vrijeme da čovjek počne razmišljati o ispravnosti življenja, jedinoj alternativi opstanka čovječanstva i života, uopšte, na Zemlji. Čovjek kao jedinka bi prvenstveno trebao da poradi na ekologiji duše i da sačuva red u samome sebi. Red u samom sebi i duhovnost su garancija reda u okolišu u kojem živi. Duhovnost je bazična dimenzija ljudskosti. Kada ljudska civilizacija izgubi duhovnost tada nastaje haos u kome se njeni temelji ruše.

Dužnost svakog čovjeka muslimana je da čuva prirodu jer njenim čuvanjem odaje priznanje Stvoritelju. Također, svaki musliman se trudi da uskladi svoj život Allahovoj volji što je, ustvari, najveći doprinos jer živjeti skladno Božijoj volji znači živjeti skladno s prirodom ne remeteći njen sklad. Poštovati islam znači istovremeno poštovati osnovne ciljeve održivog razvoja u ekologiji koji su općepoznati u čitavom svijetu. Šta je održivi razvoj? Održivi razvoj je: Razvoj koji

${ }^{9}$ Izvor: Sura El Bekare, 11 i 12. 
udovoljava potrebama sadašnjih generacija ne dovodeći u pitanje mogućnost budućih generacija da udovolje svojim potrebama. ${ }^{10}$

Vrlo jednostavna definicija koja puno govori i u kojoj je sažeta činjenica da sve treba uzimati s mjerom, poštovati cilkličnost i opću zakonitost u prirodi (Allahov sklad) jer ma koliko nama ljudima naizgled prirodno izgledalo haotično i neuređeno sve ono je upravo tako jer tako treba da bude da bi održalo ekološku ravnotežu na planeti i osiguralo opstanak društva. Na nama je da li ćemo to ispoštovati i uspjeti održati emanet.

\section{LITERATURA}

1. Čaušević, M., Dž. ef. i Pandža M., hfz. (1937) Kur'an Časni, Prevod i Tumač, Sarajevo (dostupno u PDF-u:

https://www.yumpu.com/xx/embed/view/LwCfT39OnIoquyGp, (preuzeto: 22. 10.2020)

2. IPPC (2013) Annex III Glossary. Intergovernmental Panel on Climate Change. ed.

Planton.Serge,https://www.ipcc.ch/site/assets/uploads/2018/02/WG1AR 5_AnnexIII_FINAL.pdf (dostupno: 14. 11. 2019).

3. Krznar, T. (2007) René Descartes i suvremeno shvaćanje prirode. Socijalna ekologija, 16 (1): 59-78.

4. Muhamedagić, F., Cero, M., Veladžić, M., (2020) Ekologija i održivo upravljanje okolišem, Univerzitetski udžbenik, Bihać.

5. The Smil, V. (2003) The Earth's Biosphere: Evolution Dynamics and Change. MIT Press. p. 107.

6. Tjell, C. J. (2005) Is the 'waste hierarchy' sustainable? (Editorial). U: Waste Management \& Research, 23: 173-174.

7. UNEP (1995) United Nation Environment Programme, Global Biodiversity Assessment, Cambrige University Press. Cambrige.

8. Withgott, J. i Brennan, S. (2005) Biodiversity and Conversation Biology. In: Environment, the sciences behind the stories, Pearson, Bewamin Cummings. San Francisco, CA.

9. WMO (2018) Strate of the Global Climate in 2018, WMO Statement on the State of the Global Climate (preuzeto: 10. 12. 2019).

${ }^{10}$ Izvor: Izvještaj Brundtland komisije - Our Common Future 
10. WRI, IUCN, UNEP (1992) Global Biodivbersity Strategy, Guidelines for Action to Save, Study, and Use Earth's Biotic Wealth Sustanaibly and Equitably, Report. In consultation with FAO, UNESCO, (preuzeto: 1. 11. 2019). 
dr. sci. Fatima Muhamedagić, assistant professor

University of Bihać

Biotehnical faculty

Email:fatima.mubamedagi@gmail.com

dr. sci. Mirsad Veladžić, full professor

University of Bihać

Biotehnical faculty

Email:mveladrio@yahoo.com

\section{ANALYSIS OF THE ROLE OF MAN IN THE ENVIRONMENT AND THE GLOBAL ECOLOGICAL PROBLEMS OF TODAY WITH A BRIEF REVIEW OF ISLAM}

\section{ABSTRACT}

Man in ecology as a multidisciplinary scientific field is one of the key ecological factors of the environment. Viewed historically, in its existence it is constantly changing and influencing the natural environment and adapting it to its needs. Namely, considering in general, we are witnesses that today's situation on Earth is greatly disturbed from the point of view of human influence and ecology. We are also witnessing multiple changes and consequences of environmental damage that occur in the context of global environmental problems or even environmental crises. Some of the major environmental problems faced by today's man are: climate change, the emergence of the "greenhouse effect", damage to the ozone layer and the emergence of so-called. ozone "boles", pollution of environmental media such as soil, water and air, biodiversity loss, waste, uncontrolled exploitation of natural resources, radioactivity, desertification and more. Global ecological problems, i.e. their emergence, are associated with the emergence of an irrational relationship and the creation of a rift between man himself and nature. In addition to the above, their occurrence is also associated with the effects of various sources of environmental pollution. Precisely because of all the above, the paper analyzes and deals with the role of man as an ecological factor and some of the listed global environmental problems of today, taking into account the short Islamic aspect.

Key words: ecology, ecological factors, man, global ecological problems 
الدكتور المحاضر السيدة فاطمة محمدآغيتش

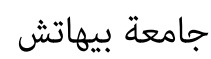

كلية التقنية الحيوية

E-mail: fatima.muhamedagic@gmail.com

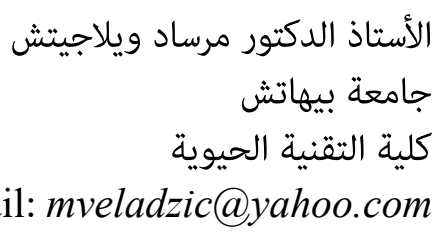

تحليل دور الإنسان في البيئة والمشكلات البيئية العالية اليوم مع تطرق موجز

\section{للإسلام}

\section{الخلاصة}

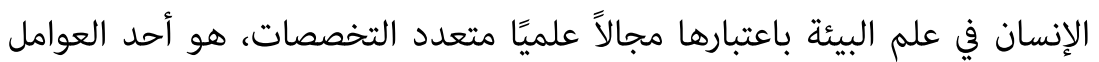

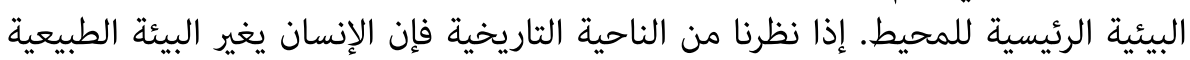

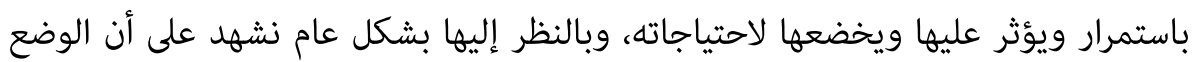
الحالي على الأرض مضطرب بشكل كبير من حيث التأثير البشري التري على الى البيئة، كما نشهد أيضًا

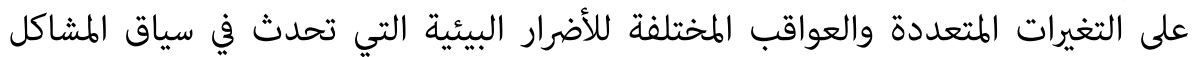
البيئية العالمية أو حتى الأزمات البيئية.

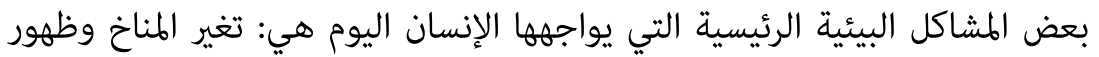

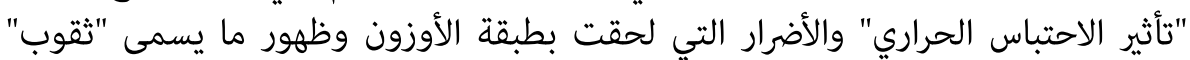

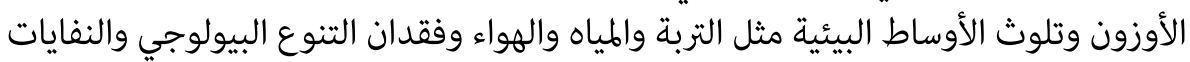

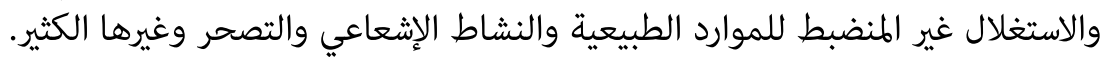

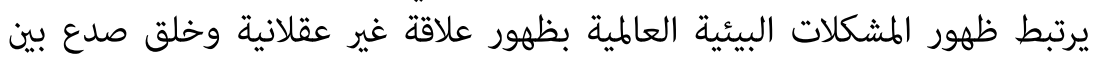

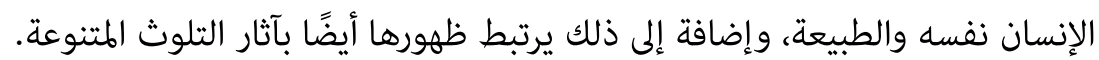

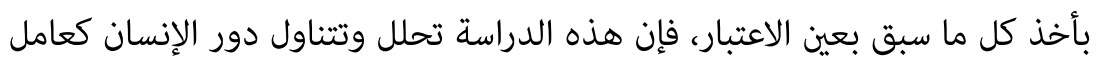

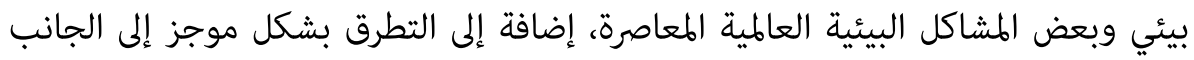
الإسلامي.

الكلمات المفتاحية: البيئة، العوامل البيئية، الإنسان، المشكلات البيئية العالية. 